\title{
Humanisme et politique en France à la fin du Moyen Âge.
} En hommage à Nicole Pons, édité par C. BOzzolo, C. GAUVARD et H. MILLET

\section{Maria Colombo Timelli}

\section{OpenEdition}

\section{Journals}

Édition électronique

URL : https://journals.openedition.org/studifrancesi/22287

DOI : 10.4000/studifrancesi.22287

ISSN : 2421-5856

Éditeur

Rosenberg \& Sellier

\section{Édition imprimée}

Date de publication : 1 avril 2020

Pagination : 149-150

ISSN : 0039-2944

\section{Référence électronique}

Maria Colombo Timelli, « Humanisme et politique en France à la fin du Moyen Âge. En hommage à Nicole Pons, édité par C. Bozzolo, C. gauvard et H. millet », Studi Francesi [En ligne], 190 (LXIV | I) | 2020, mis en ligne le 01 avril 2020, consulté le 03 août 2021. URL : http://journals.openedition.org/studifrancesi/ 22287 ; DOI : https://doi.org/10.4000/studifrancesi.22287

Ce document a été généré automatiquement le 3 août 2021.

\section{(c) $(i)(2)$}

Studi Francesi è distribuita con Licenza Creative Commons Attribuzione - Non commerciale - Non opere derivate 4.0 Internazionale. 


\title{
Humanisme et politique en France à la fin du Moyen Âge. En hommage à Nicole Pons, édité par C. BOzzolo, C. GAUVARD et H. MILLET
}

\author{
Maria Colombo Timelli
}

\section{RÉFÉRENCE}

Humanisme et politique en France à la fin du Moyen Âge. En hommage à Nicole Pons, édité par C. Bozzolo, C. Gauvard et H. Millet, Paris, Éditions de la Sorbonne, 2018, 262 pp.

1 Ce beau volume, dédié à la mémoire de Nicole Pons, réunit douze contributions centrées sur des textes qu'elle a découverts, sur des auteurs qu'elle a fréquentés, voire sur des approches qu'elle a préconisées au cours de sa carrière de chercheuse: sa bibliographie, pp. 7-10, permet de mesurer à la fois la richesse et la cohérence d'un parcours d'historienne dont rendent compte plus amplement les Témoignages et l'Introduction dus à Carla BOzzolo, Ezio ORNATO, Claude GAUVARD et Hélène MILLET (pp. 11-25).

2 Une première partie, À la recherche des textes, s'ouvre par la contribution de Bénédicte SÈRE, qui applique la méthode déjà adoptée par N.P. pour les textes polémiques aux recueils de documents et pièces ayant pour objet le Grand Schisme (Exhumer les dossiers polémiques à l'époque de Charles VI: une intuition, un chantier, pp. 29-37). Suit l'étude du manuscrit fr. 23138 de la BnF: les notes de son propriétaire, Nicolas de Lespoisse, greffier du Parlement, permettent de dessiner le profil intellectuel d'un lecteur du début $\mathrm{du} \mathrm{Xv}^{\mathrm{e}}$ siècle désirant tirer des leçons des événements auxquels il assiste (Isabelle GUYOT-BACHY, Culture historique et lecture de l'histoire: Nicolas de Lespoisse et son exemplaire des chroniques de Guillaume de Nangis, BnF, fr. 23138, pp. 39-56). Le recueil épistolaire de Gérard Machet (manuscrit BnF, lat. 8577), personnage important de la première moitié 
$\mathrm{du} \mathrm{Xv}^{\mathrm{e}}$ siècle, est examiné par Franck COLLARD: son intérêt est celui d'une source documentaire pour l'histoire du monde universitaire et ecclésiastique dans les années 1430-1440 (La correspondance entre source et genre. Réflexions sur les lettres de Gérard Machet, confesseur de Charles VII, évêque de Castres, vers 1380-1448, pp. 57-74). Le Registre delphinal de Mathieu Thomassin (1456) permet de prendre la mesure du conflit qui opposa la couronne de France et le duché de Savoie au sujet de certaines possessions autour de Vimy (Kathleen DALY, De la diplomatie à l'histoire: le «fait de Vimers» (env. 1436-1456), la France, le Dauphiné et la Savoie, pp. 75-88).

3 La deuxième partie s'organise autour des «Cercles d'intellectuels» dont Nicole Pons était une spécialiste reconnue. Nathalie GOROCHOV postule l'existence d'un préhumanisme parisien qui se serait diffusé en milieu universitaire à partir des années 1330 , avec notamment la création du collège des Lombards et autour de personnages importants, tels André de Florence et Roberto dei Bardi (Maîtres et étudiants italiens à Paris au XIV siècle: à la recherche de figures pré-humanistes, pp. 91-102). Sur le modèle de Pétrarque, Nicolas de Clamanges créa un recueil de lettres qui constituent certes des témoignages biographiques, mais dont le but est surtout d'offrir des modèles à imiter, sorte de «manuel de correspondance» humaniste (Dario CEсCHETTI, «Iocosae litterae»: choix de genre, exercice de style ou témoignage biographique? Quelques considérations sur l'épistolographie de Nicolas de Clamanges, pp. 103-122). Camille ROUXPETEL revient sur une autre question qui a intéressé Nicole Pons dès les débuts de ses recherches, à savoir les débats sur le célibat des clercs et l'éventuelle influence de l'Eglise orientale à l'époque du Grand Schisme (Philellénisme et réforme pendant le Grand Schisme: Guillaume Saignet et les Grecs, pp.123-139). Lucie JOLLIVET se penche sur l'analyse du meurtre de Louis d'Orléans menée par les humanistes parisiens, Nicolas de Clamanges et Alain Chartier, et par les universitaires, Pierre d'Ailly et Jean Gerson, afin de contrer les motivations avancées en milieu bouguignon (Le milieu humaniste et la réhabilitation de Louis d'Orléans, pp.141-157). Clémence REVEST présente enfin le poème latin où Antonio Astesano exprime son éloge des merveilles de France, en le considérant comme une tentative, isolée pour le moment, de transférer la rhétorique antique de matrice italienne au-delà des Alpes (La France décrite par Antonio Astesano, secrétaire de Charles d'Orléans, pp. 159-170).

4 "La pensée politique des intellectuels" constitue le focus de la troisième et dernière partie. Les représentations visuelles des dynasties française et anglaise pendant la guerre de Cent Ans constituent un volet essentiel de la littérature de propagande: Marigold Anne NORBYE en montre l'intérêt et souligne l'impact visuel de ces diagrammes généalogiques, qui synthétisent parfois de longs débats (Le diagramme et la politique: messages visuels dans les chroniques généalogiques des rois de France, pp. 173-190). Une autre lecture en parallèle du texte et des images est proposée par Anne D. HEDEMAN pour le manuscrit genevois du Des cas des nobles hommes et femmes, traduction par Laurent de Premierfait du De casibus de Boccace. Offert à Jean de Berry par Martin Gouge, ce codex présente une iconographie qui se veut le reflet des événements majeurs du début du $\mathrm{XV}^{\mathrm{e}}$ siècle (L'imagerie politique dans les manuscrits supervisés par Laurent de Premierfait, pp. 191-207). Jean-Marie MOEGLIN interroge enfin les traités contre les Anglais rédigés entre 1400 et 1470 afin de mesurer leur poids dans la mise en place de l'histoire de la guerre de Cent Ans (Relire les traités contre les Anglais de la guerre de Cent Ans, pp. 209-221). 
5 La Conclusion est confiée à Jean-Philippe GENET, qui rappelle les aspects les plus marquants des recherches de Nicole Pons en rapport avec les contributions des savants qui ont bien voulu lui rendre hommage par ce volume même (pp. 223-233). Index des noms de personnes (pp. 235-242) et des noms de lieux (pp. 243-246) faciliteront la consultation en mettant en relief des récurrences qui coïncident souvent avec les objets d'étude de la dédicataire. 